\title{
Erratum
}

\section{Effect of dietary fatty acid intake on prospective weight change in the Heidelberg cohort of the European Prospective Investigation into Cancer and Nutrition - Erratum}

\author{
Katharina Nimptsch, Gabriele Berg-Beckhoff and Jakob Linseisen
}

First published online 12 February 2010

doi:10.1017/S1368980009993041, Published by Cambridge University Press 15 January 2010

In the Results section of the Abstract, the sentence

Linear associations also existed for ALA and arachidonic acid intake, significantly so in women.

should read as follows:

Linear associations also existed for linoleic and arachidonic acid intake, significantly so in women.

and

In multinomial models, women in the highest tertile of ALA and stearic acid intake showed increased OR (95\% CI) for small weight gain $(1 \cdot 16(0 \cdot 94,1 \cdot 88)$ and $1 \cdot 24(1 \cdot 08,1 \cdot 43)$, respectively), and large weight gain $(1 \cdot 39(1 \cdot 03,1 \cdot 88)$ and $1 \cdot 56$ $(1 \cdot 27,1 \cdot 90)$, respectively), whereas ORs were nonsignificantly increased in men.

should read as follows:

In multinomial models, women in the highest tertile of stearic and linoleic acid intake showed increased OR (95\% CI) for small weight gain $(1 \cdot 16(0 \cdot 94,1 \cdot 88)$ and $1 \cdot 24(1 \cdot 08,1 \cdot 43)$, respectively), and large weight gain $(1 \cdot 39(1 \cdot 03,1 \cdot 88)$ and $1 \cdot 56(1 \cdot 27,1 \cdot 90)$, respectively), whereas OR were nonsignificantly increased in men.

\section{Reference}

Nimptsch K, Berg-Beckhoff G and Linseisen J. Effect of dietary fatty acid intake on prospective weight change in the Heidelberg cohort of the European Prospective Investigation into Cancer and Nutrition, First View article doi:10.1017/S1368980009993041 Published online by Cambridge University Press 15 January 2010. 